\title{
LA PUBLICIDAD PROCESAL Y EL DERECHO A LA INFORMACIÓN FRENTE A ASUNTOS JUDICIALES. ANÁLISIS GENERAL REALIZADO DESDE LA DOCTRINA Y JURISPRUDENCIA ESPAÑOLA
}

\author{
INFORMATION ON JUDICIAL MATTERS IN LIGHT OF THE \\ PRINCIPLE OF PUBLIC PROCEDURE AND THE RIGHT TO BE \\ INFORMED. GENERAL REACH ANALYSIS FROM THE PERSPECTIVE \\ OF SPANISH SCHOLARSHIP AND JURISPRUDENCE
}

\section{Francisco J. Leturia I.}

\begin{abstract}
RESUMEN: Las informaciones periodísticas sobre litigios pendientes parecen estar amparadas doblemente: por el principio de publicidad de las actuaciones judiciales y por la libertad/ derecho a la información. En materia procesal, ambos parecieran referirse al mismo objeto, e incluso ser coincidentes. Pero la distinción y tratamiento diferenciado de ambos derechos sigue siendo relevante y necesario, pues uno busca proteger la integridad del proceso, mientras el otro busca contribuir a la formación de la opinión pública sobre asuntos de interés general, lo que traerá diferentes consecuencias. Asimismo, será relevante a la hora de restringir o reglamentar, ponderar desde una u otra perspectiva.
\end{abstract}

Palabras clave: Derecho a la información, publicidad procesal, ponderación, juicios paralelos

\begin{abstract}
News reports on pending litigation seem to be protected in two ways: by the principle of public judicial proceedings, and by freedom of/right to information. In procedural matters, both appear to refer to the same object, and even to be coincident. But the distinction and differential treatment of both rights remains relevant and necessary, since one seeks to protect the integrity of the process, while the other seeks to contribute to the formation of public opinion on matters of general interest. Also, it is relevant when it becomes necessary to restrict or regulate practical situations, performing the analysis from one perspective or the other.
\end{abstract}

Keywords: Right to information, public procedure, consideration, parallel trials

\section{INTRODUCCIÓN}

En los permanentes y muchas veces ásperos debates relativos a la publicidad que los medios de comunicación dan a los procesos judiciales, así como a las acciones de facilitación de dicha información que ofrecen los distintos partícipes del proceso, para argumentar a favor de la legitimidad de la difusión, se suelen mencionar dos derechos fundamentales:

* Abogado (PUC). Doctor en Derecho de la Universidad de Salamanca. Profesor de la Facultad de Derecho de la Pontificia Universidad Católica de Chile y Presidente del Centro Nacional de Arbitrajes. Dirección postal: Alameda 340 piso 4 (Facultad de Derecho UC), Santiago de Chile. Dirección electrónica: fjleturia@uc.cl. 
la publicidad procesal y la libertad de expresión (especialmente en sus vertientes de libertad de informar y derecho a recibir información).

A simple vista, ambos derechos parecen tener, al menos en esta materia, un campo de acción y un objetivo coincidente: hacer públicos los procesos judiciales y permitir la fiscalización y libre crítica de los mismos, imponiéndose sobre otras pretensiones jurídicas (protección de la honra, presunción de inocencia, facilitación de la investigación, protección de testigos y peritos, etc.).

Podría pensarse que la publicidad procesal es una modalidad de derecho/libertad de información expresada en clave procesal ${ }^{1}$, de la que emanan dos principios confluyentes: el derecho a ser juzgado en público y el derecho del público a observar y escrutar el funcionamiento de la justicia. Y aunque esta explicación es tentadora, un análisis más minucioso nos llevará a concluir que ambos derechos deben ser entendidos como diferentes, tanto por su origen y desarrollo histórico, como por sus características, objetivos y posibilidades de protección. Además, y por qué no decirlo, por cuestiones prácticas de efectividad y garantía.

Un primer criterio de distinción surge de considerar que la publicidad de las actuaciones judiciales es básicamente una garantía procesal, que tiene por objeto prioritario facilitar la realización de un juicio justo.

La legitimidad de la difusión de informaciones relativas a los procesos pendientes y al funcionamiento general del sistema de administración de justicia, en cambio, se basa en la necesidad propia de cualquier sociedad democrática, de poner en conocimiento de la opinión pública los hechos de interés general, en forma pronta, suficiente y con la menor cantidad de restricciones posibles. Su objetivo principal es, por tanto, más institucional y político que procesal. Para decirlo de otra forma: la publicidad protege el proceso. La información o la crítica a la estructura de la justicia, es más propia de la libertad de información.

Naturalmente, frente a ambos derechos pueden plantearse situaciones que justifiquen regulaciones o restricciones. Pero ellas serán balanceadas de modos muy diferentes si estamos considerando como elemento justificativo los derechos de las partes dentro del juicio, los requerimientos de una correcta administración de justicia, o el interés institucional de contar con información oportuna y suficiente para contribuir a la formación de la opinión pública. Más aún, podremos ver casos donde en cierta forma, ambos derechos entrarán en tensión.

Iniciaremos el desarrollo de nuestro argumento advirtiendo que no profundizaremos sobre el contenido de la libertad de expresión, ni del tratamiento que la doctrina ha dado a la libertad/derecho a la información, por ser materias bien conocidas y desarrolladas ${ }^{2}$.

Aclarado lo anterior, comenzaremos con una breve alusión a la publicidad procesal.

\footnotetext{
Sobre todo considerando que según el artículo 117.1 de la Constitución española, la justicia emana del pueblo.

2 Baste con decir que el Tribunal Constitucional español ha señalado que la información es un elemento nuclear para la configuración del Estado Social y Democrático de Derecho (STC 54/2004; 158/2003 y 21/2000) y que sin ella no hay ni sociedad libre ni soberanía popular (STC 6/1981).
} 


\section{LA PUBLICIDAD PROCESAL FRENTE A TERCEROS COMO GARANTÍA INDIVIDUAL, CON IMPACTO INSTITUCIONAL}

El derecho a ser juzgado en un juicio público ha sido una de las garantías jurídicas más antiguas y universalmente reconocidas. Hoy existe consenso en considerarlo como un requisito básico del debido proceso, y de la mano de este, como uno de los pilares de la democracia y del Estado de Derecho ${ }^{3}$. En tal calidad ha sido incorporado, de una manera u otra, en todos los catálogos de derechos fundamentales ${ }^{4}$.

Esta exigencia, distintiva del proceso judicial, busca garantizar a todas las personas que las actuaciones y resoluciones judiciales que pueden afectarles estarán sujetas a múltiples mecanismos de control, que incluso superan los de tipo institucional (apelaciones, recursos disciplinarios, etc.). La presencia de una multitud de personas en la sala de audiencia y el acceso al expediente y la difusión de su contenido por parte de los medios de comunicación, para que sean conocidos por todos los miembros de la sociedad, son ejemplos de estos mecanismos de control indirecto, no dirigido, y ajeno a la esfera estatal.

La especial protección del proceso se justifica por las graves consecuencias que pueden derivar de una sentencia judicial, especialmente en el ámbito penal. Debemos considerar que quienes intervienen en un proceso estarán, por ese solo hecho, en una situación de particular vulnerabilidad 5 . Finalmente, existe una necesidad política y social de que la comunidad tenga una justa confianza en la corrección y efectividad del sistema judicial ${ }^{6}$. Todo ello justifica echar mano a mecanismos de control adicionales, que permiten el escrutinio y exposición público del proceso en forma libre, masiva e informal.

La publicidad de los juicios nace como una garantía procesal individual, pero estructuralmente beneficia a todas las personas que puedan participar de un proceso o verse afectados por su desarrollo, incluyendo a los magistrados y demás funcionarios del órgano judicial, así como del sistema jurídico como un todo ${ }^{7}$, cumpliendo también un objetivo

3 STC 96/1987. En la Constitución española está recogido en los artículos 24.2, 120.1 y 120.3.

4 Se le ha reconocido como uno de los elementos que constituyen la garantía del debido proceso o bien como un derecho autónomo. También ha sido consagrado como un derecho de rango legal. Ver a modo de ejemplo los artículos 6.1 de la CEDH, el artículo 14.1 del PIDCP de 1966 y el artículo 10 de la Declaración Universal de DD.HH. de 1948, la enmienda sexta de la CA y el artículo 8 de la Convención Americana. En España está protegido y reconocido como derecho fundamental, en el artículo 24.2 de la CE (1978), y luego como garantía procesal en el artículo 120.1 del mismo texto. A nivel legal, el artículo 232.1 de la LOPJ reproduce el artículo 120.1 de la CE. El artículo 1 del Reglamento 1/2005, sobre las cuestiones accesorias a los procedimientos, hace referencia al artículo 232 LOPJ recién mencionado.

5 Orenes (2008) p. 213, haciendo referencia especialmente a las limitaciones de que puede ser objeto la publicidad y la libertad de información en estas situaciones.

$6 \quad$ Más aún, podría decirse que esta garantía busca realmente asegurar el respeto de la ley y la confianza en el Estado de Derecho, y dando una determinada estructura al proceso, logra como consecuencia la protección de los derechos de las partes. Ella sería, por tanto, una consecuencia natural de una medida establecida en protección de un interés general.

STC 96/1987, FJ 2. La Corte Europea de Derechos Humanos (CEDH) ha señalado en la sentencia del caso Sutter v. Suiza (No 8209/78), de 22 de febrero de 1984, párrafo 26, que "el carácter público de los procedimientos ante órganos judiciales (...) protege a los litigantes de una administración de justicia en secreto, sin escrutinio público; también es uno de los medios por los que se puede mantener la confianza en los tribunales superiores e inferiores. Al hacer visible la administración de justicia, la publicidad contribuye a lograr (...) un 
institucional y de interés general, relacionado con la confianza en el Estado de Derecho y en los órganos jurisdiccionales.

La relevancia de la vigencia universal de la publicidad como un derecho fundamental, y de su vertiente institucional (vertiente que con mayor o menor intensidad puede encontrarse en cualquier garantía o derecho fundamental), queda en evidencia, por ejemplo, cuando vemos que quienes participan en un juicio podrían preferir que este fuese realizado con publicidad limitada o incluso sin ella, argumentando que ella puede tener un efecto negativo sobre sus intereses personales. Ese deseo deberá ser generalmente rechazado, pues lo buscado va mucho más allá de las partes. Del mismo modo, cuando razones de interés público justifiquen restringir la publicidad en un juicio, el consentimiento de las partes no será considerado como una razón para permitirla.

Respecto a la publicidad relativa a las partes, la situación es distinta, pues su defensa requiere que conozcan, oportuna y cabalmente, las acusaciones y pruebas que se esgrimen en su contra. Pero el mismo argumento permite sostener que este ejercicio no corresponde propiamente a una exigencia de publicidad del proceso, sino más bien a un requisito de un derecho mucho más elemental: el derecho de defensa ${ }^{8}$ o a la bilateralidad de la audiencia9 Por ello, es difícil imaginar situaciones en que se restrinja la publicidad frente a las partes de un juicio.

La publicidad como elemento del proceso se refiere a los terceros ajenos al caso $^{10}, \mathrm{y}$ va mucho más allá del círculo de las personas presentes en las audiencias, pues hace referencia a una proyección general del caso hacia la comunidad, lo que en la actualidad, solo puede lograrse con la ayuda de los medios de comunicación ${ }^{11}$.

juicio justo". Ver también caso CEDH No 332/57, Lawless v. Irlanda, del 14 de noviembre de 1960, párrafo 13; CEDH No 4451/70, Golder v. Reino Unido, de 21 de febrero de 1975, párrafo 18; CEDH No 7984/77, Pretto and others v. Italia, de 8 de diciembre de 1983, párrafo 11; y CEDH No 8273/78, Axen v. Alemania, de 8 de diciembre de 1983, párrafo 12.

Bravo apunta que: "Cierto es que hay un alto interés por conocer lo que sucede en el interior de los tribunales que se traduce en una creciente demanda de información. Por esta razón, si en su origen la publicidad procesal era concebida como instrumento de garantía a favor del inculpado, en la actualidad aumenta la importancia que se concede a la vertiente institucional del principio de publicidad y a su vinculación con el derecho a difundir información sobre la actuación de la justicia”. Bravo (2012) p. 47.

8 STC 96/1987, FJ 2.

9 Méndez de Lugo y López de Ayala (1999) p. 175-176; Instrucción 3/2005, 7 de abril de 2005, "sobre las relaciones del Ministerio Fiscal con los medios de comunicación”.

10 Gimeno (1998) p. 295.

11 La STC 30/1982, referida al Consejo de Guerra que investigaba el fallido Golpe de Estado de Tejero, señala, respecto a la expulsión de la sala de audiencias a un periodista del "Diario 16", que "el principio de publicidad de los juicios, garantizado por la Constitución, implica que estos sean conocidos más allá del círculo de los presentes en los mismos, pudiendo tener una proyección general. Esta proyección no puede hacerse efectiva más que con la asistencia de los medios de comunicación social, en cuanto tal presencia les permite adquirir la información y transmitirla (...). Este papel de intermediario natural desempeñado por los medios de comunicación social entre la noticia y cuantos no están en condiciones de conocerla directamente, se acrecienta respecto a acontecimientos que por su entidad puede afectar a todos y por ello alcanzan una especial resonancia en el cuerpo social, como ocurre indiscutiblemente con el desarrollo de la vista de la causa que nos ocupa" (...) "los representantes de los medios de comunicación social, al asistir a las sesiones de un juicio público, no gozan de un privilegio gracioso y discrecional, sino que lo que se ha calificado como tal es un derecho preferente atribuido en virtud de la función que cumplen, en aras del deber de información constitucionalmente garantizado 
En efecto, la presencia de un reducido grupo de personas (publicidad inmediata), se deberá considerar, en general, insuficiente para los objetivos de control social del proceso que este derecho busca ${ }^{12}$.

La necesidad de recurrir a los medios masivos de difusión para hacer realidad el principio de publicidad procesal es una de las circunstancias que más genera una idea de semejanza con la libertad de información, pues en la práctica se confunde con el derecho de cualquier persona a entrar a la sala de audiencias y difundir masivamente lo que en ella observa, así como sus opiniones. Y aunque la publicidad procesal es, en principio, un derecho de observación más que de difusión, en la práctica de las sociedades masivas, se realiza mediante la difusión de un relato que alguien ha realizado ${ }^{13}$.

Adicionalmente, el derecho a ser juzgado en público fue un emblemático anhelo ilustrado, reactivo a los procesos secretos de tipo inquisitorial, donde muchas veces la única actuación pública era la ejecución de la sentencia ${ }^{14}$. Por ello, la publicidad también ha estado asociada a exigencias políticas que trascienden el ámbito estrictamente procesal, y que hoy pueden observarse en todas las reformas vinculadas a la transparencia de las actuaciones del Estado, el acceso a la información pública, etc. ${ }^{15}$. En este desarrollo, sí se encuentra conectado con la libertad de expresión y el derecho a la información.

Los riesgos de este "estatuto de garantías" son difíciles de evitar, por los espacios que ofrece para una serie de situaciones potencialmente problemáticas y altamente complejas, como por ejemplo, los llamados “juicios paralelos"16, entendidos como una versión no de-

(...)”. En el mismo sentido, la STC 56/ 2004, FJ 3. Por su parte, la STC 57/2004 señala en su FJ 5 que: "En una sociedad industrial desarrollada, como la de hoy, el simple acceso del público es insuficiente para garantizar el control democrático de la Justicia a que se ha orientado históricamente el principio de publicidad judicial inmediata".

La Recomendación 13 (2003) del Comité de Ministros del Consejo de Europa, relativo a las informaciones sobre procedimientos penales en medios de comunicación, aprobada el 10 de julio de 2003, reitera la importancia de la libertad de los periodistas para informar sobre el sistema penal y el derecho del público de recibir información sobre estas materias (incluyendo servicios policiales), para lo cual se debe facilitar el trabajo de la prensa y su acceso a los juicios.

En un sentido similar se ha pronunciado el Tribunal Supremo. STS 1646/1994.

12 Roxin (1999) p. 92.

13 STC $178 / 1993$.

14 Cabe señalar que pese a lo oscuros y cuestionables que estos procesos hoy puedan parecernos, constituyeron un avance frente al ejercicio de la actividad punitiva del estado no sujeta a regulación.

15 Según Del Riego: "El principio de publicidad surge en el Siglo XIX, un siglo después de que nacieran los periódicos tal y como hoy los concebimos, y a lo mejor esto no es casual. En España, el principio de publicidad de las actuaciones judiciales surge de la mano del liberalismo e inmediatamente fue constitucionalizado, con una doble finalidad: proteger a las partes de una justicia sustraída al control público, y por otro, mantener la confianza de la comunidad en los tribunales, constituyendo así una de las bases del debido proceso y uno de los pilares del Estado de Derecho”. Del Riego (2012) p. 119. En el mismo sentido, RodríGUEZ (2000) pp. 206-207.

El voto particular del Magistrado Rodríguez-Zapata Pérez en la STC 57/2004 señala en su punto 4 que "a esa finalidad sirve el principio, acuñado en la Revolución Francesa frente al proceso inquisitorial y secreto de la Justicia del Antiguo Régimen, que, tras Voltaire, se conoce como de 'apertura a todos de las Salas de justicia' ('Tous les interrogatoires se font a portes ouvertes')".

16 Leturia (2018). La complejidad del sistema legal hace difícil el cumplimiento de los objetivos de la publicidad, favoreciendo su transformación en espectáculo. Pedraz (1990) p. 115-130. 
seada de las necesarias informaciones y opiniones que pueden formularse sobre los procesos en curso.

En su versión abusiva, estas modalidades comunicativas, más que constituir acciones amparadas por una garantía para quienes intervienen en un proceso, pueden afectar sus derechos, ofreciendo de paso un instrumento de penalización social anticipada y fuera de los márgenes y controles del Derecho ${ }^{17}$.

\section{DIFERENCIAS FUNDAMENTALES ENTRE LIBERTAD DE INFORMACIÓN Y PUBLICIDAD PROCESAL}

La concepción de la publicidad recién expuesta se asocia fuerte y naturalmente con la libertad de información, con la que tiene una profunda unidad de propósitos y una serie de semejanzas, al menos cuando la información protegida se refiere a un asunto judicial. Por ello, Rodríguez-Zapata Pérez señalaba que "el derecho comparado muestra que es muy difícil trazar una línea de separación entre las exigencias de la libertad de información y las garantías de un juicio justo" 18 .

Ello ha permitido sostener que la publicidad de los asuntos judiciales tiene una doble protección constitucional, o lo que es lo mismo, una protección especialmente reforzada, en la gran mayoría de los $\operatorname{casos}^{19}$.

Sin embargo, por más que pueda correctamente afirmarse que el principio de publicidad y el de información cumplen objetivos similares, y que el desarrollo del primero pudiera incluso ser suficiente para contener al segundo ${ }^{20}$, hay muchas razones para la consagración de ambas en forma separada.

La primera de ellas tiene que ver con el desarrollo parcialmente divergente que la doctrina ha hecho del mismo, en buena medida por razón de su historia ${ }^{21}$, y de las especialidades jurídicas que las han tratado.

La segunda es que, dada su importancia procesal, es conveniente, más allá de sus matices en cuanto a límites y contenidos, despejar toda duda sobre su vigencia. Una protección por vía indirecta, como sería la que ofrecería la libertad de información, podría terminar dando una equivocada idea de una protección secundaria o consecuencial, cuando lo que se quiere es relevar su importancia y hacerla indiscutible, por vía de la interpretación. Al mismo tiempo, limitarse a la publicidad procesal dejaría sin cobertura las actuaciones previas y posteriores al juicio. Si a eso sumamos la omisión de la publicidad procesal como

17 Orenes (2008) p. 50.

18 El voto particular del Magistrado Rodríguez-Zapata Pérez en la STC 57/2004 señala en su punto número 1 que "el derecho comparado muestra que es muy difícil trazar una línea de separación entre las exigencias de la libertad de información y las garantías de un juicio justo”.

19 Del Riego (2012) p. 119. Este planteamiento es consistente con lo propuesto por el Anteproyecto de la Ley de Enjuiciamiento Criminal de 27 de julio de 2011, que atribuye más importancia a la presencia de medios de comunicación que de personas en las salas de audiencia de juicio.

20 Couture llamaba la atención sobre la conexión entre el modelo democrático y la posibilidad de controlar y fiscalizar colectivamente a los jueces que existía. Couture (1962) p. 192. En el mismo sentido, López (2006) p. 98.

21 En España ambas aparecen consagradas por primera vez en la Constitución de Cádiz de 1812. 
derecho autónomo en algunos textos constitucionales (España, Chile, entre otros, donde se debe recurrir a la tesis de los "derechos implícitos"), dejaría abiertos espacios para la interpretación y restricción de la misma ${ }^{22}$.

Finalmente, podemos decir que la publicidad procesal busca alcanzar algunos objetivos que sería difícil realizar por medio del ejercicio de la libertad de información, dada su especificidad procesal y orientación al adecuado desarrollo del proceso.

La publicidad procesal está establecida para velar por la imparcialidad del juez y la calidad del proceso, por lo que su restricción se justificaría cuando el efecto logrado sea el opuesto. En estos casos, sin embargo, se podrá seguir argumentando en favor de la publicidad, pero desde la libertad de información, basándose en el interés superior de la sociedad de estar al tanto de los asuntos judiciales, así como de la forma en que se administra justicia, materias en las que casi sin excepción puede encontrarse un interés público real.

Estas situaciones muestran la importancia de conceptualizar ambos derechos en forma separada. Muchos de los roces que se producen en estas materias, provienen precisamente de realizar un análisis solamente basado en uno de ellos, típicamente los superiores intereses de la administración de justicia, y no en las necesidades propias de una sociedad democrática, que reclama información y escrutinio sobre todos los órganos del Estado y sobre todos los asuntos de interés general ${ }^{23}$. Las restricciones que en algunos países se pretende imponer a los fiscales respecto de la información que manejan, relativos al avance de la investigación (al menos en sus aspectos generales), es un claro ejemplo de ello.

\section{ANÁLISIS COMPARATIVO DE POSIBLES RESTRICCIONES A AMBOS DERECHOS}

\subsection{Posibles Restricciones a la publicidad procesal o JUdicial}

La publicidad ofrecida dentro del marco judicial tiene por objeto la protección del proceso, por lo que en estricto rigor no es un fin en sí mismo, sino que tiene carácter instrumental. Pese a ello, en buena medida por las garantías que ofrece y el contexto histórico de su nacimiento europeo (a lo que se suma hoy su coincidencia con la libertad/derecho a la información como requisito esencial de la democracia) ha existido una tendencia a omitir una realidad común a cualquier derecho: que puede tener diferentes gradaciones e intensidades dependiendo de las circunstancias en que es ejercido, los tipos de proceso y las personas y materias a que se refiera ${ }^{24}$.

Naturalmente, la publicidad tendrá su mayor expresión en el ámbito del proceso penal, pues de él puede seguirse la imposición de las más severas medidas que contempla el ordenamiento jurídico. Nada obsta a que en otros tipos de procesos, la exigencia de publi-

22 En un plano más práctico, en España, la consagración de la publicidad del proceso como derecho fundamental abre la vía al recurso de amparo (art. 53.2 de la Constitución española) y obliga a que solo pueda ser regulado por Ley Orgánica, respetando su contenido esencial y bajo un criterio de proporcionalidad. ORENES (2008) p. 51.

23 Peral (2007) pp. 220-226.

24 STS 168/1995 señala que las restricciones deben ser excepcionales y fundamentadas en otro derecho constitucional, conforme al principio de proporcionalidad. 
cidad pueda ser modulada, disminuida o restringida en atención de otros bienes jurídicos relevantes, o de los intereses de la partes, siguiendo la lógica del balanceo aplicable a todos los derechos fundamentales.

De esta manera, muchas veces incluso serán las propias exigencias del proceso las que limiten la publicidad ${ }^{25}$. Incluso, en situaciones donde el interés público comprometido es menor (algunos casos de arbitrajes ${ }^{26}$, procedimientos monitorios, etc.) las restricciones o modulaciones a la publicidad podrán justificarse en la posibilidad de dar protección a otros derechos, o simplemente en necesidades de economía y simplificación procesal, en ausencia de un interés público que justifique lo contrario.

El Tribunal Europeo de Derechos Humanos se ha referido expresamente a la posibilidad de limitar la publicidad procesal ${ }^{27}$. En el mismo sentido lo ha hecho el Tribunal Supremo de los Estados Unidos ${ }^{28}$ y el Tribunal Constitucional Español, recordando que el propio artículo 120.1 de la Carta Fundamental ha señalado para la publicidad "las excepciones que prevean las leyes de procedimiento", y ellas deberán ser establecidas haciendo uso de los criterios establecidos por un juicio de ponderación ${ }^{29}$.

Así ocurrirá, por ejemplo, en aquellas situaciones que pueden afectar a menores ${ }^{30}$, a víctimas de delitos sexuales, o en general, donde el interés público no es lo suficientemente significativo en comparación con el privado, como en general ocurre con los casos de fami$\operatorname{lia}^{31}$, o en lo que ahora ha venido a llamarse "derecho al olvido"32.

Las medidas restrictivas a la publicidad podrán ser de carácter total o parcial, aunque estas últimas cumplirán con más facilidad el requisito de ser siempre las mínimas necesarias

\footnotetext{
25 Brennan (2012) p. 192-193. Los artículos 6 y 10 de la Convención Europea de Derechos Humanos son derechos diferentes y se encuentran en niveles diferentes, y su ubicación ya nos indica el predominio del primero, por lo que se encuentra sistemáticamente en un nivel más elevado de protección. El Tribunal Europeo de Derechos Humanos ha estimado lo contrario.

26 En materia arbitral, ampliamente utilizada en el mundo mercantil y de seguros, hay quienes propician la publicidad, pero más por razones de conocimiento de la jurisprudencia y de los criterios arbitrales que por otras razones. Aunque esta razón también se vincula al debido proceso, tiene un alcance más general.

27 El Tribunal Europeo de Derechos Humanos ha señalado que el artículo 6 autoriza a excluir de un juicio a la prensa y el público ya sea "en interés del orden público o de la seguridad nacional en una sociedad democrática" o porque "la protección de la vida privada de las partes en el proceso así lo exijan" o bien "en circunstancias especiales la publicidad pudiera ser perjudicial para los intereses de la justicia”. Señala también que exigir que los procedimientos disciplinarios se lleven a cabo con público impondría una carga desproporcionada a las autoridades. CEDH Nº 7819/77 y 7878/77, Campbell and Fell v. Reino Unido, de 28 de junio de 1984.

28 Con el caso Sheppard v. Maxwell, 384 U.S. 333 (1966), vinculado a la anulación de un juicio realizado en presencia de una fuerte campaña de prensa (que precedió no solo al juicio sino a la elección en que participaban el juez y del fiscal) mostró la posibilidad de restringir, por motivos justificados, la publicidad sobre determinados asuntos, así como el riesgo que la prensa podía implicar para el adecuado funcionamiento de la justicia.

29 STC 57/2004, FJ 5.

30 STC 36/1991, FJ 6.

31 Artículo 6 de la Convención Europea de Derechos Humanos y artículo 14 de la Convención Americana sobre Derechos Humanos. En materia civil, ver el artículo 138 LECivil.

32 Ver Mezzanotte (2009).
} 
para lograr el objetivo buscado ${ }^{33}$. Asimismo, según lo requiera cada caso, podrán referirse al orden de los contenidos, al personal, espacial, temporal o técnico ${ }^{34}$.

Muchas veces estas restricciones no afectarán necesariamente al conocimiento de lo obrado, e incluso podría decirse que los objetivos de la publicidad procesal se mantuvieron intactos pese a la restricción, como por ejemplo cuando se limita el acceso a un determinado tipo de medio (generalmente audiovisual) a la sala de audiencia, por el efecto perturbador que ejerce sobre los participantes. Podrían incluso imaginarse situaciones donde la publicidad frente a terceros se logre sin la mediatización de la prensa, como de hecho ocurre en todos los casos que no alcanzan el estrellato mediático ${ }^{35}$.

Por otro lado, cuando una persona comunica hechos vinculados a un proceso, la libertad de información le permite cubrir un ámbito mucho mayor que el estrictamente procesal. No pareciera claro que todas las opiniones relativas al caso se relacionen con la publicidad procesal, ni menos con informar, por ejemplo, sobre el desempeño de un juez en otros casos, o sobre ciertos rasgos de su personalidad observados en su biografía, aunque bien pueden quedar cubiertos por los derechos asociados al interés público noticioso. Al mismo tiempo, si el objetivo de la publicidad procesal es solo la protección del proceso, podrían presentarse dudas sobre el tratamiento que deba darse a la sentencia definitiva más allá de su lectura y notificación, pues el proceso ya se encuentra terminado y no habría nada que proteger.

Pero es evidente que la corrección de la sentencia se verá también estimulada por los controles posteriores que puedan realizarse, así como por los trabajos de análisis jurisprudencial, lo que justifica su publicidad incluso más allá de los límites del derecho al olvido (referido a difusión masiva de informaciones allí donde el interés público de la noticia ha disminuido).

\subsection{Posibles restricciones a la libertad de información (sobre asuntos JUDICIALES)}

El ejercicio de la libertad de información y de expresión puede afectar otros derechos fundamentales, incluyendo los relacionados con el derecho a un juicio justo ${ }^{36}$, ya sea afec-

33 STC 56/2004, FJ 3. Fácilmente pueden interpretarse estos preceptos en el sentido, conforme con el artículo 232.2 LOPJ (que se refiere a la posibilidad de "limitar el ámbito de la publicidad"), de que permiten al órgano judicial adoptar también una medida intermedia entre la audiencia pública y la celebración de la sesión a puerta cerrada si, como consecuencia del juicio de proporcionalidad o ponderación que realice, se llega al resultado de que, por las circunstancias del caso, basta para la protección de los bienes o derechos en peligro con la exclusión de la entrada de determinados medios técnicos de captación o difusión de información, como podrían ser las cámaras fotográficas, de vídeo o televisión. En el mismo sentido se pronuncia la STC 57/2004, FJ 5.

34 Art. 232.2 LOPJ (ver además STC 65/1992, FJ 2).

35 Así parecen insinuarlo algunas sentencias del Tribunal Europeo de Derechos Humanos (Caso Carolina de Hannover, fallado primero por el TC alemán y luego confirmado por la CEDH). En el mismo sentido, STC 139/2001, FJ 2, y STC 127/2010, FJ 2.

36 En el estudio barómetro número 2861 CIS de febrero de 2011, algunas preguntas se refieren a la administración de justicia. Respecto a la pregunta de si los medios de comunicación eran capaces de determinar las decisiones de la justicia, un $8.9 \%$ se manifestó muy de acuerdo, un 36\% de acuerdo, un 12\% ni de acuerdo ni en desacuerdo. Menos de un 30\% se manifestó en desacuerdo (23.3\%) o muy en desacuerdo (4.4\%). Pero se 
tando la imparcialidad, los derechos de las partes, la presunción de inocencia, y muchos otros bienes jurídicos de quienes participan de una u otra forma en un proceso ${ }^{37}$.

Por ello, el Convenio Europeo autoriza expresamente, en su artículo 10.2, las restricciones y regulaciones a la libertad de expresión cuando ella tiene por objeto una causa legítima y justificada, dentro de las cuales menciona "la autoridad e imparcialidad del Poder Judicial" 38 .

Sabemos que la propia lógica de la ponderación impide establecer listas taxativas de causales de limitación de un derecho fundamental. Por ello, aún sin estar expresamente mencionadas en una Constitución o un tratado, podrían considerarse otras causales vinculadas con la administración de justicia y con los derechos envueltos en la misma, a la hora de establecer restricciones legítimas a las libertades de expresión e información. Por ejemplo, podrían invocarse con este propósito la protección de los derechos de las partes y otros intervinientes, el debido proceso, la presunción de inocencia, entre otras ${ }^{39}$, debiendo seguirse los mismos estándares señalados en el artículo 10.2. Por tanto, las medidas que restrinjan la libertad de expresión e información con el objeto de salvaguardar la autoridad del Poder Judicial y la imparcialidad de los órganos judiciales deben estar autorizadas por ley, perseguir un fin legítimo, y ser necesarias y proporcionadas dentro del marco exigido por una sociedad democrática (lo que implica, entre otras cosas, que deben ser mínimas, excepcionales y generalmente transitorias).

Adicionalmente, cualquier restricción en estas materias debe ser excepcional y sólidamente fundada ${ }^{40}$. Por ello tanto el Tribunal Supremo de los Estados Unidos como la Corte Europea e Interamericana de Derechos Humanos han señalado que el criterio a utilizar es el del "peligro claro e inminente", y no el del simple riesgo ni menos una estructura rígida de causales, pues la publicidad y la libertad de expresión alcanzan un interés máximo en los asuntos judiciales, especialmente los de naturaleza penal ${ }^{41}$.

destaca el alto grado de confianza en la independencia de los jueces ordinarios, tanto como de los miembros del Tribunal Supremo y del Tribunal Constitucional.

37 La capacidad de la prensa para afectar los intereses de las partes y la realización de la actividad jurisdiccional ha sido comentada y puesta en relieve por numerosa doctrina y jurisprudencia. Para un estudio más completo ver Prat Westerlindh, (2013).

38 Esta cláusula habría sido incorporada en el texto a petición del Reino Unido (la autoridad e imparcialidad del Poder Judicial, expresión que debía interpretarse que incluye la protección de los derechos de los litigantes). CEDH N 31457/96, News Verlags GmbH \& Co.KG v. Austria, de 11 de enero de 2000, párrafo 45.

39 Por la misma razón, la ausencia de mención expresa en este sentido que vemos en el Pacto de Derechos Civiles y Políticos y en la Convención Americana de Derechos Humanos, no puede considerarse como una desprotección a dichos intereses o como el establecimiento de un estándar diferente, bastando para ello recurrir a la doctrina de los derechos implícitos o tácitos.

$40 \quad$ Nebraska Press Assn. v. Stuart, 427 U.S. 539 (1976).

41 Dow Jones \& Co., Inc. v. Simon, 488 U.S. 946 (1988). La prohibición de una manifestación a las afueras del edificio de los tribunales no estaría relacionada con la protección de su autoridad e imparcialidad (United States v. Grace, 461 U.S. 171 (1983). Ver además Valldecabres (2004) p. 224 y los casos allí citados. 


\section{ANÁLISIS DE ALGUNAS LIMITACIONES, MEDIDAS E INSTITUCIONES CUYO OBJETO ES PROTEGER LA AUTORIDAD DE LOS TRIBUNALES, LA IMPARCIALIDAD JUDICIAL Y EL DERECHO A UN JUICIO JUSTO Y QUE SUPONEN UNA RESTRICCIÓN LEGÍTIMA Y JUSTIFICADA DE LA PUBLICIDAD DE LOS ASUNTOS JUDICIALES}

Sabemos que las medidas restrictivas deberán ser establecidas atendiendo las circunstancias concretas en que se manifiesten, mediante un juicio de ponderación, teniendo especial cuidado de que sean mínimamente invasivas y obedezcan a razones poderosas y apremiantes. Por ello, cualquier limitación deberá ser excepcional e idealmente temporal, permitiendo que la libertad de expresión vuelva a su máxima extensión a la brevedad. Adicionalmente, dados los objetivos buscados, ellas podrían recaer también en partes ajenas al proceso, como pueden ser los medios de comunicación ${ }^{42}$.

Otras restricciones a la libertad de información y a la publicidad pueden también basarse en la necesidad de salvaguardar otros derechos o principios constitucionales, como la protección de la infancia o la seguridad nacional, el orden público, además de las que protegen al mismo tiempo diversos derechos (intimidad y honra del inculpado e imparcialidad del tribunal, por ejemplo). Analizaremos algunas de ellas.

\subsection{Censura y limitación a la PUblicación de DETERMinADAS INFORMACIONES}

La censura, total o parcial, o la prohibición de informar sobre algunas materias, parece a primera vista un mecanismo muy eficaz para evitar expresiones que puedan afectar la imparcialidad, el debido proceso y los derechos de las partes, aunque por su severidad y riesgos se le considera, en forma bastante universal, como una medida poco recomendable. Aunque aún es común verlas, creemos que sobre este tipo de medidas existe una "presunción de inconstitucionalidad".

Dado que en general se ha aceptado una mayor necesidad de proteger a los jurados que a los jueces profesionales frente a las publicaciones e influencia de la prensa, es común encontrar allí a una mayor variedad de medidas. Pero ellas no han sido realmente efectivas si solo alcanzan restricción de las fuentes informativas y no la prohibición efectiva de informar sobre un hecho particular (y de informar sobre la prohibición misma a su vez) ${ }^{43}$.

Mayor consenso existe frente a prohibiciones informativas específicas y transitorias frente a determinadas personas (peritos o testigos) y frente a la reproducción de medios de prueba ilícitos (dado que un principio fundamental del proceso penal moderno es que solo se puede considerar en un juicio los antecedentes aportados legítimamente al mismo y tratados en forma pública, como puede verse en el artículo 353 número 3 del Código Penal alemán). Asimismo, algunos autores admiten la posibilidad de establecer una prohibición de publicar el contenido de lo obrado antes de que ellos sean hechos públicos conocidos (lo

42 Nebraska Press Assn. v. Stuart, 427 U.S. 539 (1976); y CEDH No 13585/88, The Observer and Guardian v. Reino Unido, de 26 de noviembre de 1991.

43 Nebraska Press Assn. v. Stuart, 427 U.S. 539 (1976). Especialmente la parte resolutiva del fallo. 
que generalmente ocurre en la etapa de juzgamiento propiamente tal), evitando así el desarrollo de condenas anticipadas y juicios paralelos ${ }^{44}$.

Conviene tener en consideración la limitada capacidad de respuesta que los jueces tienen, debido a que su rol les impone una capacidad limitada del ejercicio de su libertad de expresión fuera del proceso ${ }^{45}$. Para protegerlos frente a ataques injustificados que deterioren la justa confianza que la comunidad debe tener en ellos, es posible establecer algún tipo de límites y regulaciones ${ }^{46}$. Este sería un claro ejemplo de restricciones a la libertad de expresión e información relativas a juicios que no afectan al principio de publicidad, al menos en forma significativa.

\subsection{LiMiTACIONES AL ACCESO A LA INFORMACIÓN DEL PROCESO, ESPECIALMENTE EN LA FASE}

DE INVESTIGACIÓN. REFERENCIA AL SECRETO DE SUMARIO Y AL CONTEMPT OF COURT

Si los órganos del Estado deben contribuir a realizar los mandatos constitucionales, los actores judiciales deberían facilitar a los medios el acceso a la información sobre los procesos judiciales. Considerando que -más allá de los deseos de las partes y algunos magistrados y fiscales- ella será de todos modos conocida, parece mejor que se pongan los medios para que ello suceda en forma completa, oportuna, veraz y respetuosa de los derechos que podrían ser afectados ${ }^{47}$.

Por ello, en España se ha dispuesto que incluso los Fiscales del Ministerio Público contribuyan en facilitar el acceso a la prensa de la investigación que disponen, tomando los resguardos necesarios para salvaguardar, en la mejor medida de lo posible, los objetivos y derechos en juego ${ }^{48}$.

Pero al igual como sucede con la información entregada por los diferentes actores públicos vinculados a la administración de justicia (Gabinetes de Prensa, etc.), sin duda de gran valor, ella solo puede considerarse como una fuente adicional de información ${ }^{49}$, que en ningún caso puede sustituir el derecho colectivo de conocer de primera mano el desarrollo de un proceso judicial.

Nos parece interesante resaltar que el acceso a las actuaciones judiciales que requiere la opinión pública no precisa ser inmediata o directa, sino que puede verse facilitada por la intermediación y organización que de estos eventos realicen los medios de comunicación. Sin embargo, no puede argumentarse en la forma inversa. La exigencia de publicidad procesal no puede considerarse satisfecha dando a los medios un acceso indirecto a lo obrado en una audiencia, por lo que las restricciones en este sentido deberían ser mínimas ${ }^{50}$.

\footnotetext{
$44 \quad$ Roxin (1999) p. 78.

45 CEDH N ${ }^{\circ}$ 15974/90, Prager and Oberschlick v. Austria, de 26 abril de 1995, párrafo 34.

46 CEDH No 31611/96, Nikula v. Finlandia, de 21 de marzo de 2002, párrafo 48.

47 No entraremos en el debate de si la investigación es una etapa propiamente jurisdiccional o no lo es. Si no lo fuera, se le parecería bastante, y el principio de la publicidad sería igualmente válido, siempre con menor intensidad que en la etapa de juicio propiamente tal.

48 Instrucción 3/2005 del Ministerio Fiscal español, sobre las relaciones con los medios de comunicación.

49 STC 57/2004, FJ 6.

50 STC 56/2004; y STC 57/2004, FJ 3 señalan que: “(...) la asistencia de los representantes de los medios de comunicación social a las sesiones de un juicio público no tiene lugar en virtud de un privilegio gracioso y dis-
} 
Volviendo a la cuestión principal, y más allá del deber general de los órganos del Estado de colaborar con el trabajo de la prensa y la formación de la opinión pública en materias de interés general, es evidente que circunstancias especiales podrían llevar a restringir el acceso a ciertos materiales antes del enjuiciamiento, para facilitar el éxito de la investigación y asegurar la protección de los derechos de los involucrados, tomando medidas de protección que podrían llegar hasta la reacción penal ${ }^{51}$.

En España, así como en otros países herederos de su tradición jurídica, la figura del secreto de sumario ha buscado este objetivo, aunque en la mayoría con poco éxito, generando un cuestionamiento transversal, así como una serie de propuestas correctivas, tanto desde la doctrina como desde el marco normativo.

Sin embargo, parecen existir otras posibilidades menos invasivas y más efectivas, que ya han probado suerte en el derecho comparado. En este campo, una de las instituciones más características del sistema procesal anglosajón es el Contempt of Court, habitualmente traducido como desacato. Algunas de sus modalidades permiten decretar sanciones civiles y penales contra cualquier acto que pudiera afectar la imparcialidad del tribunal y afectar de este modo el proceso. Sin embargo, ella ha tenido distintas lecturas en el tiempo y según la tradición jurisdiccional que se observe. El Tribunal Supremo de los Estados Unidos, por ejemplo, con una lógica más moderna y proclive a la libertad de expresión, ha señalado que el criterio tradicional, que permite reaccionar frente a cualquier situación que tenga una probabilidad de provocar un perjuicio a la autoridad judicial o al proceso, debía ser reemplazada por el criterio de "peligro grave e inminente". En el mismo sentido se pronunció la Corte Europea de Derechos Humanos al conocer el caso Sunday Times, ${ }^{52}$ que obligó al Reino Unido a dictar normas especiales para adaptar esta tradicional institución a las exigencias de una sociedad democrática, y de la que han salido reglamentaciones que parecen mucho más interesantes para el resto de los actores globales ${ }^{53}$.

En efecto, luego de estas reformas, algunos autores han valorado la flexibilidad que este mecanismo ofrece para proteger la imparcialidad judicial y la integridad del proceso, y que superarían con creces otras medidas más rígidas, como por ejemplo el secreto de sumario ${ }^{54}$.

Por otro lado, algunos autores han propuesto medidas parciales más rígidas y permanentes, y compatibles con el objetivo general de protección del proceso y formación de una opinión pública libre. Roxin, por ejemplo, señala que basta con que se hagan públicos los

crecional, sino de un derecho preferente atribuido en virtud de la función que cumplen, en aras del deber de información constitucionalmente garantizado ex artículo 120.1 CE (STC 56/2004, FJ 3); y, de otro, que, siendo las audiencias públicas judiciales una fuente pública de información, forma parte del contenido del derecho que tienen los profesionales de la prensa la obtención de la noticia en la vista pública en que esta se produce (...)”. Asimismo, la STC 57/2004 en su FJ 4 dispone que: "las audiencias públicas judiciales son, pues, una fuente pública de información y, por eso (...) con respecto a los profesionales de la prensa escrita, que forma parte del contenido de su derecho a comunicar información la obtención de la noticia en la vista pública en que esta se produce".

51 Un excelente trabajo en este sentido es el de VALLDECABres (2004).

52 CEDH No 6538/74 The Sunday Times v. Reino Unido, de 26 de abril de 1979.

53 Para un mayor estudio sobre el Contempt of Court, ver Miller (2000).

54 Ver Leturia (2014). 
distintos avances formales realizados durante la instrucción, como pueden ser la detención, arresto, registro domiciliario, interposición de la denuncia o la querella, etc., pues no existiría ningún interés público informativo prevalente sobre los detalles en los avances de la instrucción o sobre los nuevos logros de las autoridades persecutorias ${ }^{55}$.

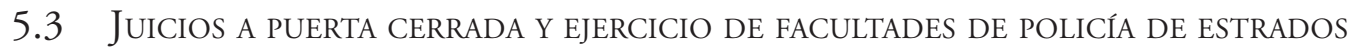

Una rotunda excepción al principio de publicidad es la que permite la realización de juicios a puerta cerrada. Debido a la amplitud de las causales que permiten decretarlo en España, podría incluirse dentro de las medidas tendientes a proteger el proceso mismo, la imparcialidad judicial o los derechos de los intervinientes ${ }^{56}$. En efecto, se permite su adopción "cuando así lo exijan razones de moralidad o de orden público, o el respeto debido a la persona ofendida por el delito o a su familia" 57 . Obviamente, ella no alcanzará a las partes del juicio, y deberá emanar de una resolución fundada y construida sobre la base de un juicio de proporcionalidad ${ }^{58}$.

Incluso, si la reserva de información fuera fundamental, se podría negar la tramitación de un caso que podría afectar dicha confidencialidad ${ }^{59}$, aunque dicha situación será siempre excepcional y extrema.

Pero aún frente a los casos señalados, el propio Ministerio Fiscal ha señalado que pueden admitirse gradaciones ${ }^{60}$

Una situación similar puede derivarse de la facultad llamada "policía de estrados", establecida con carácter general en el artículo 232.2 de la Ley Orgánica del Poder Judicial y que les permite limitar la publicidad de las audiencias, por razones de orden público y de protección de los derechos de los intervinientes. El ejercicio de esta facultad deberá ser excepcional y requerirá una resolución fundada, pues corresponde a una medida extrema, y no a la sola comodidad de los participantes ${ }^{61}$.

Sin embargo, alguna jurisprudencia americana ha señalado que el principio de publicidad incluso alcanza a las audiencias realizadas en forma privada ${ }^{62}$. A nuestro juicio, en este tipo de situaciones debe distinguirse el hecho mismo de que la audiencia sea realizada

\footnotetext{
55 RoXIN (1999) p. 88.

56 Otro caso especial de restricción a la publicidad, aunque fundado en otros motivos, son los vinculados a asuntos confidenciales, reservados o secretos. En estas circunstancias, es posible que se facilite el acceso a los mismos, pero imponiendo a quienes tengan acceso a ellos especiales exigencias de reserva, incluso sancionadas penalmente, como sucede por ejemplo en EE.UU.

57 El artículo 680 de la Ley de Enjuiciamiento Criminal (LECrim).

58 Del mismo modo, existen otras leyes que se refieren a limitaciones de la víctima de publicidad no deseada, recaído sobre la víctima o sobre la persona imputada. Ley de delitos violentos y contra la libertad sexual, (35/1995), la Ley Orgánica sobre Responsabilidad Penal de Menores (5/2000). El CEDH también se ha pronunciado en este sentido en T. v. Reino Unido, específicamente en el párrafo 86; $V$. v. Reino Unido, párrafos 88 y 90; y P. v. Reino Unido, párrafos 37 y 38.

59 Totten v. United States, 92 U.S. 105 (1876); United States v. Reynolds, 345 U.S. 1 (1953); y Weinberger v. Catholic Action of Hawaii, 454 U.S. 139 (1981).

60 Instrucción 3/2005, p 45.

61 STC 57/2004, FJ 5.

62 Dow Jones \& Co., Inc. v. Simon, 488 U.S. 946 (1988).
} 
sin participantes externos, de la necesidad y conveniencia que puede existir de proteger algunos bienes jurídicos relevantes por la vía de restringir su publicidad.

\subsection{LiMitaCiONES A LA PUBLICIDAD POR RAZONES DE ESPACIO FÍSICO}

Resulta evidente que en los casos donde la concurrencia de público a la vista de una causa sea mayor que las posibilidades físicas del tribunal, deberán imponerse restricciones de acceso y priorizaciones. A nivel estadístico, estos casos son de extraña ocurrencia, pero corresponden precisamente a aquellos que despiertan un mayor interés en la opinión pública.

En estos casos, la restricción es forzosa, no solo por razones de orden práctico o material, sino de salvaguardia del adecuado desarrollo del proceso y de la seguridad de quienes participan en él, incluyendo el propio público.

Para no afectar innecesariamente la garantía de la publicidad, se podrán decretar conjuntamente medidas que permitan paliar en parte sus efectos negativos, dado que la motivación es eminentemente práctica, y no busca realmente limitar la publicidad. En este sentido, han existido interesantes experiencias en cuanto a facilitar el acceso y la vista de la audiencia por medios tecnológicos (incluyendo su transmisión masiva por vía electrónica o televisada), la preferencia otorgada a los representantes de medios de comunicación de mayor alcance y sintonía, e incluso la realización del juicio en un espacio de mayor capacidad (cambio de sede del tribunal) ${ }^{63}$. En ningún caso el principio de publicidad podría quedar reducido a guardias y funcionarios, aun cuando la vista de la causa se lleve a cabo dentro de la prisión. En estos casos, "la publicidad queda garantizada con la presencia de ciertos testigos e incluso del público ordinario (al margen del mediático) y el derecho del público a recibir información de lo que acontece durante el mismo se obtiene por otras vías" ${ }^{4}$. Finalmente, las deliberaciones de los jueces no parecen quedar incluidas dentro del principio de publicidad. Hay buenas razones para mantener este espacio bajo confidencialidad, sin perjuicio que luego se expongan en la sentencia las conclusiones a que se lleguen ${ }^{65}$.

63 Esta posibilidad está expresamente autorizada por el artículo 268.2 de la LOPJ, y ha sido utilizada por la Audiencia Nacional en algunos juicios vinculados a la ETA y al 11M (caso en que se arrendó una sede en la Casa de Campo, que costó al Ministerio de Justicia más de 1 millón de euros). Esta tuvo una cobertura máxima, estableciéndose una señal institucional de audio y video a los que podían acceder los medios. Además, no se grabó a las víctimas ni a policías, no hubo primeros planos, y se facultó al presidente para suspender la grabación accionando un botón. Las audiencias provinciales han seguido estos parámetros para casos de alto interés público (ver, por ejemplo, casos recientes citados por Orenes RuIz (2008) p. 85, nota 46). STC 56/2004, FJ 6; STC 30/1986, FJ 5. Se señala que las restricciones vinculadas al espacio son medidas de seguridad que no desvirtúan el carácter público del proceso.

64 Valldecabres (2004) p. 384.

65 Artículo 233 LOPJ. Lo mismo se ha señalado incluso para las deliberaciones del Tribunal Supremo de los Estados Unidos. Ver opinión disidente del Juez Warren E. Burguer, en New York Times Co. v. United States, 403 U.S. 713 (1971). YolDI (2012) p. 161: "Las deliberaciones de los plenos del CGPJ son igualmente secretas. Sin embargo, siempre hay al menos media docena de vocales en disposición de contar, con pelos y señales la versión que más les beneficie”. 


\subsection{ProhibiCIONES DE INGRESO O RESTRICCIONES A DETERMINADAS PERSONAS O} MEDIOS DE COMUNICACIÓN A LA AUDIENCIA

La presencia de medios al interior de la sala de audiencia, y especialmente de medios audiovisuales, ha despertado una fuerte polémica respecto de su capacidad para alterar el comportamiento de los asistentes, dañando la imparcialidad del tribunal y el buen desarrollo del proceso. La importancia y complejidad de este punto pueden verse en las sentencias STC 56 y 57/2004, que precisamente se refirieron a intentos de regular este tipo de filmaciones $^{66}$. Este punto es relevante porque la necesidad de pluralismo propio de la libertad de expresión, no necesariamente es una necesidad de la publicidad, aunque ciertamente se beneficia de ella. Pero podría considerarse bien satisfecha la exigencia de publicidad con un pluralismo limitado.

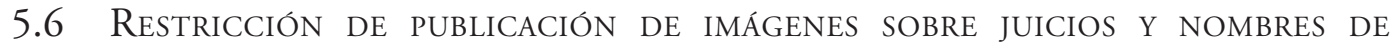 INVOLUCRADOS}

Una posibilidad de restricción parcial de la publicidad de los juicios se relaciona con las limitaciones a la difusión de imágenes y nombres de personas (testigos, inculpados, víctimas de ciertos delitos, entre otras) $)^{67}$.

Ella puede estar fundada o bien en las necesidades del proceso, como por ejemplo cuando se quiere evitar presiones sobre testigos o peritos, o bien en otros derechos más permanentes, ateniendo que la divulgación de dichos elementos realizan un aporte secundario en el proceso de formación de la opinión pública y no contribuyen al control de la actividad estatal, sino por el contrario, incluso pueden desviar la atención a asuntos menos relevantes pero más atractivos desde la perspectiva de la curiosidad.

Esta distinción es muy relevante, porque las restricciones establecidas en favor del proceso son por esencia transitorias, y deben terminar cuando se dicta sentencia. Si el objetivo ha sido garantizar otros derechos, las restricciones pueden ir más allá del término del mismo.

Los ejemplos en este sentido son numerosos. El Tribunal Constitucional prohibió publicar fotografías de un incendio ${ }^{68}$ por considerar que no tenían interés informativo per se. Sin embargo, tuvo un criterio diferente frente a la publicación de imágenes de una víctima de homicidio ${ }^{69}$.

El Tribunal Europeo de Derechos Humanos ha señalado que la restricción a publicar la fotografía de un imputado, puede ser considerada como una forma de proteger la autoridad e imparcialidad del Poder Judicial, y que por esa vía alcanza la protección de los

\footnotetext{
${ }_{66}$ En mucha menor medida, pero con una postura mucho más proclive a permitir la grabación de los juicios por medios audiovisuales, la instrucción 3/2005 del Ministerio Fiscal.

67 Yoldi (2012) p. 163.

68 STC $13 / 1985$.

69 ATC 195/1991, FJ 6: "Que la televisión retransmitiera fotografías del fallecido constituye una actividad de difusión que también aparece salvaguardada por la Constitución, en su art. 20, al versar sobre una realidad social que reviste interés público (...) siempre que consistiera en información obtenida al margen de la causa, y sin transgredir ninguna limitación legítimamente ordenada por la autoridad judicial (STC 13/1985)" (parámetros expuestos por la Comisión Europea de Derechos Humanos, decisión de 22 julio de 1963, Núm. 1793/63).
} 
derechos de los litigantes ${ }^{70}$. Pero también señaló que la restricción concreta (publicar las fotografías de un imputado) no era necesaria para proteger los derechos reclamados, por lo que constituía una interferencia injustificada en la libertad de expresión ${ }^{71}$.

En casos de "derecho al olvido" se ha autorizado restringir la publicidad dada a condenas anteriores de un testigo o imputado, cuando ello puede afectar la imparcialidad de miembros del jurado. Si bien en estos casos también se protege la honra, ello es en forma secundaria y residual, y luego de terminado el objetivo de protección de la imparcialidad del tribunal (y presunción de inocencia del afectado), es posible volver al estado anterior ${ }^{72}$.

El Tribunal Supremo de los Estados Unidos ha mostrado una mayor resistencia a la restricción de la publicidad procesal. A modo de ejemplo, podemos señalar que desestimó la alegación de una persona que durante la tramitación de un juicio de divorcio había sido fotografiada sin su consentimiento y luego publicada, argumentando que en los procesos judiciales existía un interés público ${ }^{73}$. Este caso llama especialmente la atención pues es precisamente en este tipo de situaciones donde la privacidad podría prevalecer en forma más evidente sobre el interés público informativo.

Asimismo, el Tribunal Supremo de los Estados Unidos declaró inconstitucional una ley de Georgia que protegía a las víctimas y prohibía la publicación de su nombre, reiterando la importancia de una prensa fuerte (vinculando su justificación a las enmiendas 1 y 14). Con esto se constituye, de ahí en adelante, lo que se ha venido a llamar un "absolute first amendment privilege" 74 . Sin embargo, esta radicalísima postura se ha atemperado en las cortes federales y estatales ${ }^{75}$.

En España, ante la falta de normas precisas, el tratamiento del asunto queda en manos de los jueces, y ni la práctica ni la doctrina sobre estas materias es uniforme. Gómez Bermúdez y Beni Uzábal señalan, a modo de denuncia, que muchos tribunales consideran que el carácter de personaje público de algunas figuras o el hecho de que ya hayan sido condenados es razón suficiente para reducir sus derechos al mínimo a favor de la información y la publicidad, aunque otros estiman lo contrario. En el punto intermedio se encuentran aquellos que estiman que la difusión pública de la imagen del acusado puede aumentar desproporcionadamente los perjuicios de someterse a un proceso, por lo que ordenan el establecimiento de medidas especiales como la desfiguración del rostro o de la voz, las que permiten dar a conocer el hecho noticioso mismo pero sin sus detalles más singulares ${ }^{76}$.

\footnotetext{
$70 \quad$ CEDH No 31457/96, News Verlags GmbH \& Co.KG v. Austria, de 11 de enero 2000, párrafo 45.

71 CEDH No 31457/96, News Verlags GmbH \& Co.KG v. Austria, de 11 de enero 2000, párrafos 16, 18, 20, $21,37,39,40,45$ y 60 .

72 Leturia (2016a) p. 102.

73 Berg v. Minneapolis Star \& Tribune Co., 79 F Supp. 957 (Minn.1948).

74 Ver al respecto Cox Broadcasting Corp v. Cohn, 420 U.S. 469 (1975). Con ello además se contribuía a controlar la actividad gubernativa (judicial en este caso, pero propia de Gobierno). Similar pero no idéntico es el caso de Florida Star v. B. J. F., 491 U.S. 524 (1989), también referido a la legitimidad -o falta de castigo- dada a la publicación del nombre de una víctima de violación.

75 Mezzanotte (2009) p. 312.

76 Gómez y Beni (2006) p. 270.
} 


\subsubsection{Situación especial de testigos y peritos}

Una situación que nos parece particularmente interesante es la que afecta a testigos y peritos, o la que podría afectar a algunos jurados, y que buscará darles protección frente a las amenazas y presiones mediáticas.

En efecto, en un proceso judicial pueden participar y prestar declaración personas ajenas al mismo. Sus intereses serán muy diferentes a los intereses de las partes (acusador y acusado), pues no buscan un resultado ni arriesgan una condena, sino que básicamente comparecen en cumplimiento de una exigencia normativa ${ }^{77}$.

Dado que las declaraciones que hagan los terceros ajenos al juicio pueden tener una gran incidencia en el curso del proceso y en el resultado final del mismo, es preciso protegerlas de influencias. En materias donde la prueba es decisiva, como la penal, podría bastar cambiar un "si" por un "no estoy tan seguro" o "no recuerdo bien" para inclinar la balanza en un sentido u otro, o al menos, para generar una duda razonable en el juez ${ }^{78}$.

Tal posición, los hace candidatos evidentes a todo tipo de presiones, dentro de las que se encuentran las mediáticas, o el temor a reproches o represalias posteriores. Consciente de ello, el derecho buscará propiciar las condiciones para que ninguna de estas circunstancias impida a testigos y peritos prestar declaraciones apegadas al "escrupuloso respeto al deber de decir verdad y declarar exactamente lo que han sabido como peritos o presenciado como testigos"79.

Estas acciones se enmarcan dentro de uno de los objetivos centrales del derecho procesal moderno: la adecuada protección de las víctimas (directas e indirectas) de un delito y la reducción de las externalidades negativas del proceso ${ }^{80}$. Bajo esta comprensión, su ámbito será más amplio, y abarcará, por ejemplo, la protección de los menores que comparecen en un juicio ${ }^{81}$. En España, esta situación es abordada por la Ley Orgánica 19/1994 ${ }^{82}$, que pese a haber establecido una serie de medidas de tutela y protección, resulta insuficiente para los objetivos y necesidades que debiera cumplir.

\footnotetext{
77 Artículo $118 \mathrm{CE}$. El testigo está obligado a comparecer, so pena de recibir sanciones y ser llevado por la fuerza (artículos 420 de la Ley de Enjuiciamiento Criminal y 463 y 556 del Código Penal).

78 Rara vez se permitirá formar convicción condenatoria solo en base a una declaración, pero sin duda su efecto no será neutro.

79 Moreno (1998) p. 60. Cabe señalar que este riesgo fue tradicionalmente ignorado en el pasado.

80 Gimeno (2010) pp 37-39; Oromí (2012) p. 6 (al tratar los derechos y garantías procesales de la víctima en Europa).

La Directiva 2012/29/UE establece algunas normas mínimas en este sentido. Su considerando (9) señala que: "El delito constituye un injusto contra la sociedad y una violación de los derechos individuales de las víctimas (...). Se ha de proteger a las víctimas de delitos frente a la victimización secundaria y reiterada, así como frente a la intimidación y las represalias (...)”, Exposición de Motivos de la LO 19/1994 Resolución 827/1993, de 25 de mayo.

Es interesante consignar que en el I Encuentro Jueces-Periodistas la mayoría de los jueces señaló que deberían imponerse limitaciones a la libertad de información y a la publicidad procesal por razón de la persona o la naturaleza del delito, en cambio la mayoría de los periodistas opina lo contrario (pregunta 19).

81 La Directiva 2005/20 llama a reconocer la especial vulnerabilidad de los menores ante las actuaciones que exige la justicia, llamando a evitar su victimización.

82 Para un mayor desarrollo de la misma, ver FuENTEs (1996) pp. 135-162.
} 
En la materia de nuestro estudio, quizá la medida de protección más importante es aquella que permite al juez de instrucción ocultar la identidad de un tercero ajeno al litigio, utilizando en su remplazo cualquier símbolo u expresión (numérica, codificada, etcétera). Esta medida puede impetrarse tanto de oficio como a petición de parte, permitiendo incluso disponer que se omitan del expediente todos aquellos datos que permitirían la individualización de los mismos, así como tomar medidas para imposibilitar su identificación visual durante el procedimiento, o que las modificaciones sean hechas llegar a un domicilio alternativo (artículo 2 de la LO 19/94). Asimismo, el artículo 3 de la misma normativa, resalta la necesidad de impedir afectaciones vinculadas con la imagen y la información pública, al señalar que "los miembros de las Fuerzas y Cuerpos de Seguridad, el Ministerio Fiscal y la autoridad judicial cuidarán de evitar que a los testigos... se les hagan fotografías o se tome su imagen por cualquier otro procedimiento (...)".

Es importante que las medidas de protección no interfieran con los derechos de la contraparte ni interfieran con los derechos del debido proceso. Por ello, las medidas de ocultación de identidad no podrán ser mantenidas durante el juicio oral ${ }^{83}$, pues ello implicaría una vulneración a los derechos asociados al debido proceso ${ }^{84}$. Concretamente, las partes tienen derecho a conocer y contradecir todas las declaraciones existentes en un proceso, así como a conocer y contrainterrogar a cualquier testigo ${ }^{85}$, aunque luego de un juicio de ponderación, podría ser la de dar valor a las declaraciones de un testigo o perito realizadas en la etapa de instrucción, sin necesidad de citarlos nuevamente al juicio oral, siempre que ello no implique una clara situación de indefensión o merma de los derechos de defensa, o de vulneración del principio del contradictorio ${ }^{86}$. En estos casos, por ejemplo, podría siempre verificarse la fiabilidad del testigo, y exigirse que dicha declaración no sea el único elemento de prueba de una sentencia condenatoria.

Otra situación especial, para la que preferimos no crear un acápite, es la de las personas investigadas, que eventualmente podrían ser condenadas, pero que podrían exigir la máxima protección de su presunción de inocencia, especialmente frente a las informaciones que las vinculan a los hechos delictuales. Si bien esta podría considerarse antes una garantía más propia del derecho penal, es también una garantía procesal, sin pretender desconocer su mucha mayor complejidad y profundidad, imposible de alcanzar en estas páginas. A guisa de ejemplo ilustrativo, señalaremos que, para evitar la penalización anticipada, Roxin

\footnotetext{
83 Artículo 4.3 LO 19/1994.

84 Artículo 6.3 b de la Carta Europea de Derechos Humanos. Para el caso específico de la protección de las víctimas en el juicio oral, ver Pérez y Ferreiro (2006) pp. 283-302.

85 El TCE se pronunció sobre la validez de las declaraciones prestadas en dependencias policiales y luego no reproducidas en el juicio oral (STC 23/2014 FJ 4, haciendo referencia a la 53/2013, que en su FJ 4 ya sostenía que la prueba rendida en dependencias policiales no tiene valor alguno, señalando que ello podía envolver una vulneración al proceso con todas las garantías, en especial, la presencia de un tercero cuyo rol por definición normativa consista en ser imparcial. Sobre el particular, puede verse un interesante artículo de BujOSA (2013) pp. 14-22.

86 CEDH No 11454/85, Kostovski v. Paises Bajos, sentencia de 20 de noviembre de 1989; CEDH No 12433/86, Lüdi v. Suiza, sentencia de 15 de junio de 1992; CEDH No 21363/93, Van Mechelen v. Países Bajos, sentencia del 23 de abril de 1997. El TCE se ha manifestado en el mismo sentido en: STC 143/2010, de 2 de diciembre; STC 1/2006, de 16 de enero; STC 148/2005, de 6 de junio; y STC 155/2002, de 22 de julio.
} 
propone que solo se divulgue el nombre de la persona inculpada en los casos de personajes históricos o delitos graves, en cambio en los delitos menores debería preferirse el anonimato (pone como ejemplo "la única mención de la primera letra"). Además, sugiere que tal anonimato incluso debe existir en los delitos muy graves, como una forma de derecho al olvido, proponiendo como requisitos solo el paso de un largo tiempo y el cumplimiento de la condena ${ }^{87}$. En estos casos prima el derecho a la resocialización y a la honra, derivado de la personalidad, por sobre el de la información (o el de la publicidad de la sentencia).

\subsection{Suspensión y anulación de juicios}

Una de las medidas más extremas que se han adoptado para proteger la autoridad e imparcialidad judicial frente a campañas mediáticas ha sido la suspensión y anulación de los casos afectados por campañas mediáticas y juicios paralelos.

En Estados Unidos este criterio se encuentra presente desde Irvin v. Dowd ${ }^{88}$. Y se ha aplicado especialmente cuando los hechos u opiniones son capaces de crear una atmósfera de hostilidad, buscan la simpatía de la opinión pública, revelan hechos (inculpatorios o exculpatorios) que no han sido sometidos a las garantías del proceso y que no serían admitidos como prueba en el juicio o que buscan presionar a testigos, peritos y jurados. En estos casos el Tribunal Supremo de los Estados Unidos ha aplicado el canon del "peligro grave e inminente" y ha anulado condenas ${ }^{89}$.

Siguiendo este ejemplo, y sabiendo que nunca existirá un ambiente completamente aséptico, en el Derecho continental se ha planteado como una posible solución la suspensión de cualquier procedimiento cuando no están dadas las condiciones para que el juicio se desarrolle en forma justa y sin alteraciones o presiones mediáticas que puedan afectar, aun de modo inconsciente, significativamente a quienes participan en el proceso. Se podría pensar, además, que es más razonable suspender el procedimiento en cuanto se produzca el clima poco propicio, en vez de esperar la resolución final y anular todo lo obrado, pese a las dificultades que ello pueda ofrecer. El asunto es problemático, pues si no sabemos qué actos afectan al proceso, ni cómo los afectan, mal podríamos regularlos correctamente, dejando subsistir aquellos comentarios y críticas legítimas.

En España, existe consenso en que las campañas de prensa más violentas indudablemente pueden afectar a la imparcialidad de los jueces y el desarrollo de un juicio con todas las garantías, dado el natural temor que puede generar en ellos la reacción de los medios y de la opinión pública ante ciertas decisiones. Como lo reconoce el Auto 195/1991, entre otros muchos documentos y sentencias ${ }^{90}$.

\footnotetext{
87 Roxin (1999) p. 77.

88 Irvin v. Dowd, 366 U.S. 717 (1961). También Rideau v. Louisiana 373 US 723 (1963), y Cox v. Louisiana, 379 US 559 (1965).

89 Ver, particularmente la sentencia de Estes v. Texas, 381 U.S. 532 (1965).

90 A modo de ejemplo, Juanes (2012) p. 114. Quintero Olivares, por ejemplo, afirma que el hecho de que un juez no pueda conservar la ecuanimidad frente a una agresión mediática sería una prueba de que "esa persona no reúne las condiciones necesarias para ejercer la función jurisdiccional”. Rodríguez (2012) p. 151. PéreZ Morate señala que los ataques al juez pueden afectar su neutralidad y afectar la racionalidad de sus decisiones. Pérez (1999) p. 288. Aunque minoritarias, también hay opiniones en contra. Por todas ellas, ver QuINTERO
} 
Por lo mismo, y considerando las limitaciones que recaen sobre los jueces en el ejercicio de su libertad de expresión, y que les impide reaccionar frente a las críticas, el Tribunal Europeo de Derechos Humanos ha señalado que ellos deben ser especialmente protegidos frente a ataques destructivos e injustos ${ }^{91}$, sin quedar por ello exentos de críticas duras o molestas.

\subsection{OTRAS MEDIDAS SECUNDARIAS}

Existen otras medidas secundarias que en forma directa o indirecta podrían contribuir a la protección del proceso y la imparcialidad, y que podrían tener una incidencia en la publicidad procesal. Dentro del ámbito de lo regulado jurídicamente, una de ellas es el procedimiento de amparo institucional, que busca proteger la independencia e imparcialidad judicial frente a ataques realizados por terceros ${ }^{92}$, incluyendo agresiones mediáticas, pero debe ser solicitado por la parte afectada por la pérdida de imparcialidad del juez. Sin embargo, ha sido criticado por tener una efectividad restringida, que alcanzaría básicamente a "simples declaraciones de solidaridad" con poco efecto práctico ${ }^{93}$. Otras medidas, de orden extrajurídico, pueden tener un impacto muy positivo (mecanismos de autorregulación, uso apropiado y simplificado del lenguaje por parte de jueces, fiscales y periodistas, entre otros), pero exceden del ámbito de este trabajo.

\section{CONCLUSIONES}

La libertad de expresión, especialmente en sus facetas de libertad y derecho a la información, y la publicidad de las actuaciones judiciales, son garantías fundamentales que pueden coincidir en el objeto protegido y en sus efectos, aunque desde fundamentos diferentes. La primera privilegia la formación de opinión pública en asuntos de interés general, mientras la segunda busca ante todo garantizar la corrección del proceso judicial. Por ello, conviene darles un tratamiento y análisis diferenciado.

Sin embargo, cuando nos referimos a los asuntos judiciales, ambos derechos son invocados para justificar la difusión de información sobre los mismos, y evitar sus restricciones, tantas veces promovida por jueces, fiscales y por las mismas partes.

Dado que el espíritu publicista de la libertad de expresión parece más amplio que el principio de la publicidad procesal (argumentado sobre la base de que es un requisito esen-

(1999) p. 352. Sin embargo, reconoce que las críticas pueden hacer creer a la ciudadanía que la decisión del tribunal es injusta.

91 CEDH N 48898/99, Perna v. Italia, de 25 de julio de 2001, párrafo 36; CEDH N 15974/90, Prager and Oberschlick v. Austria, de 26 abril de 1995; CEDH No 19983/92, De Haes and Gijsels v. Bélgica, de 24 de febrero de 1997; y CEDH N 11508/85, Barford v. Dinamarca, de 22 de febrero de 1989.

Sin embargo, en otros casos ha valorado más la difusión del interés público involucrado. Por ejemplo, CEDH No 1377/88, Thorgeir Thorgeirson v. Islandia, de 25 de junio de 1992.

92 Art. 14 LOPJ. Cabe recordar que la imparcialidad judicial se refiere no solo a su afectación real de la imparcialidad, sino a la confianza pública sobre los tribunales, de modo de evitar que existan en la comunidad (ciudadano medio, etc.) fundadas sospechas de que la imparcialidad del juez y su lealtad a la ley están bajo peligro.

93 Orenes (2008) pp. 280-281. 
cial de la sociedad democrática, derecho preferente y más), tiene un espectro superior de protección, que podría ser restringido por razones de la correcta administración de justicia, mientras en el caso de la publicidad procesal, ella es su fundamento. De esta forma, solo con la libertad y derecho a la información podrá haber realmente, y solo en contadas oportunidades, una tensión con intereses divergentes.

En los casos en que estas situaciones se planteen, el juicio de ponderación o balanceo deberá considerar los diversos elementos en juego, obligando a regular o modelar de manera diversa una serie de situaciones. Sin perjuicio de ello, la libertad de expresión y publicidad procesal deben considerarse en conjunto a la hora de interpretar y resolver situaciones concretas $^{94}$.

Existe bastante consenso en que la publicidad "entre partes" es más bien un requisito de defensa que un derecho ponderable, por lo que la publicidad realmente relevante desde un punto de vista de análisis doctrinario es la que se garantiza a terceros ajenos al caso. También existe consenso en que ella no puede limitarse a los concurrentes a la sala de audiencia, por lo que solo puede ser realizada con la colaboración de los medios de comunicación social, conectándolo con el derecho a la información y al escrutinio ciudadano.

La problemática se vuelve especialmente interesante cuando nos referimos a la etapa de investigación de los juicios penales, porque la publicidad puede interferir con el éxito de la misma, con los derechos de las partes. Además, existe bastante consenso en que la publicidad en la etapa del juicio oral admite pocas excepciones, por la que será durante la investigación donde puedan plantearse situaciones de secreto o de restricción de la información, especialmente frente al público masivo. Por ello, la publicidad y el secreto dentro del proceso se refieren a "dos intereses primarios que no admiten subordinación: la defensa de la sociedad y la defensa del inculpado" ${ }^{95}$, y el Estado no puede desproteger ninguno de ellos ${ }^{96}$.

La publicidad judicial ha sido concebida, estructurada y elaborada para proteger el proceso, los derechos de las partes que participan en él, y la autoridad e imparcialidad de los tribunales de justicia, por lo que no tienen ningún sentido allí donde su implementación genera el efecto contrario.

La libertad de expresión, especialmente en su vertiente relacionada con la información y expresión de opiniones sobre asuntos de interés general (y los juicios, los asuntos penales/delictuales, y el funcionamiento de la justicia lo son), tiene por objeto la formación de una opinión pública robusta, suficiente y oportunamente informada, dentro de los márgenes y exigencias propios de una sociedad democrática.

Sabemos que la función institucional que la información juega dentro de una democracia (tanto material como jurídicamente) la convierten en uno de los derechos más vigorosos y que menos restricciones admiten a la hora de realizar un juicio de ponderación. De hecho, en muchas oportunidades la sola necesidad del proceso no será razón de peso suficiente para lograr la restricción de la información. Y del mismo modo, aunque en forma

\footnotetext{
94 Si sumamos el origen ilustrado del derecho y su alto contenido ideológico, a su habitual doble o triple reconocimiento (constitucional, legal, tratados internacionales vinculantes o una combinación de ellas) es natural ver un grueso y significativo desarrollo doctrinal del mismo, mucho más abundante que en otras áreas del derecho.

95 Roxin (1999) p. 87.

96 Álvarez et al. (1985) p. 175.
} 
más excepcional, podría concebirse alguna materia que no fuera de interés público y que gozara de la protección de la publicidad procesal por razón de garantía del proceso.

Existen numerosas razones para justificar la existencia de la publicidad procesal como un derecho autónomo y diverso a la libertad de información. Ponderar desde un derecho u otro arrojará respuestas distintas, y ambas en conjunto complementan análisis y permiten adoptar medidas acertadas con más claridad que si no estuvieran concebidas en forma autónoma. Dejar toda la protección del proceso entregada a la libertad de información, sería ingenuo, pareciendo más prudente relevar la importancia estructural de la publicidad procesal.

Los conflictos entre medios de comunicación y las necesidades de una correcta administración de justicia no son recientes, pero han adquirido un protagonismo sin precedentes en las últimas décadas, de la mano del desarrollo de nuevas tecnologías de captación y difusión de información. Por ello, el desarrollo doctrinario de estas materias es aún incipiente, no encontrándose a nivel comparado soluciones definitivas ni consensos sobre cómo abordar estas cuestiones. Mientras la regulación sobre estas materias sea, tanto a nivel interno como comparado, insuficiente, la imposición de medidas de resguardo en un sentido u otro quedará entregada a la prudencia de los tribunales.

La publicidad procesal puede realizarse con estándares distintos a los de la libertad de expresión e información. Las limitaciones al pluralismo informativo, derivadas por ejemplo de la falta de diversidad editorial de los medios de una sociedad, no necesariamente permitirán decir que la publicidad procesal no ha sido garantizada. Del mismo modo, no se justificará con la misma intensidad promover la intervención estatal para la remoción de obstáculos por causa de la publicidad de los juicios que cuando lo que se busca asegurar es el derecho de la comunidad a estar informado (instalar antenas repetidoras, asegurar la cobertura y acceso de zonas aisladas). Bastará con un buen grupo, considerable, suficiente, variado, para dar por asegurados los objetivos de la publicidad, y no se justificaría, en general, forzar o promover campañas de asistencia o atención a los juicios para satisfacerlo, ni menos hacer obligatorio que todos los juicios tengan público o sean cubiertos por los medios.

En todo este escenario, tener claridad sobre estos puntos parece de especial valor, y este trabajo ha buscado contribuir a ello en algún grado y medida.

\section{BIBLIOGRAFÍA CITADA}

Bravo, Gabriela (2012): "Ponencia Magistral. Derecho a la Información y Populismo Mediático”, en Ovejero, Ana María (edit.), La Presunción de Inocencia y los Juicios Paralelos (Madrid, Editorial La Ley) p. 47.

Brennan, Lord Daniel (2012): Ponencia, en Ovejero, Ana María (edit.), La Presunción de Inocencia y los Juicios Paralelos (Madrid, Editorial La Ley) pp. 192-193.

Bujosa Vadell, Lorenzo (2013): "Las Declaraciones en las dependencias policiales y el derecho a un proceso con todas las garantías (Comentario a la STC 53/2013, de 28 de febrero)". Disponible en: https://dialnet.unirioja.es/servlet/articulo? codigo=4350223. Fecha de consulta: 27 de agosto de 2017. 
Couture, Eduardo Juan (1962): Fundamentos de Derecho Procesal Civil (Buenos Aires, Editorial de Palma).

Del Riego, Carmen (2012): Ponencia, en Ovejero, Ana María (edit.), La Presunción de Inocencia y los Juicios Paralelos (Madrid, Editorial La Ley) p 119.

Fuentes Soriano, Olga (1996): "La ley orgánica 19/1994 de Protección de Testigos y Peritos en Causas Criminales", Revista de Derecho Procesal, vol. I, No 1: pp. 135-162.

Gimeno Sendra, José Vicente (1998): Constitución y Proceso (Madrid, Editorial Tecnos).

Gimeno Sendra, José Vicente (2010): Manual de Derecho Procesal Penal (Madrid, Editorial Colex, segunda edición).

Gómez Bermúdez Javier y Beni Uzábal Elisa (2006): Levantando el Velo. Manual de Periodismo Judicial (Madrid, Editorial Dossat).

Juanes Peces, Ángel (2012): Ponencia, en Ovejero, Ana María (edit.), La Presunción de Inocencia y los Juicios Paralelos (Madrid, Editorial La Ley) p 114.

Leturia, Francisco (2014): "Actividad Judicial y el Derecho a un Juicio Justo Frente a la Libertad de Expresión. Análisis de los desafíos impuestos desde el constitucionalismo contemporáneo". Disponible en: https://dialnet.unirioja.es/servlet/tesis?codigo=54336. Fecha de consulta 20 de octubre de 2017.

Leturia, Francisco (2016a): "Fundamentos Jurídicos del Derecho al Olvido. ¿Un Nuevo Derecho de Origen Europeo o Una Respuesta Típica ante Colisiones entre Ciertos Derechos Fundamentales?", Revista Chilena de Derecho, vol. 43, No 1: pp. 91-113.

Leturia, Francisco (2016b): “El Sofá con Otto y la Ley Mordaza”. Disponible en: http:// www.elmostrador.cl/noticias/opinion/2016/04/05/el-sofa-con-otto-y-la-ley-mordaza/. Fecha de consulta: 23 de julio de 2017.

Leturia, Francisco (2018): "La Problemática de los Juicios Paralelos en la Jurisprudencia y Doctrina Española”, Revista Ius et Praxis, vol. 23, No 2, segundo semestre 2017: pp. 21-50.

Miller, C. J. (2000): Contempt of court (Oxford University Press).

Mezzanotte, Massimiliano (2009): Il Diritto All'oblio. Contributo Allo Studio Della Privacy Storica (Teramo, Edizioni Scientifiche Italiane).

Moreno Catena, Víctor (1999): "La Protección de los Testigos y Peritos en el Proceso Penal Español”, Revista Penal, No 4: p. 60.

López Ortega, Juan (2006): "Información y Justicia: la Dimensión Constitucional del Principio de Publicidad Judicial y sus Limitaciones", Cuadernos de Derecho Judicial, $\mathrm{N}^{\circ}$ 16, dedicado a Justicia y Medios de Comunicación: pp. 93-136.

Orenes Ruiz, Juan Carlos (2008) Libertad de Información y Proceso Penal. Los Limites (Pamplona, Editorial Aranzandi).

Oromí Vall-Llovera, Susana (2012): "Los Derechos de la Víctima en las Reformas del Proceso Penal. Del Olvido al Resurgimiento", Revista de La Ley Penal, No 98-99: p. 6.

Pedraz Penalva, Ernesto (1990): “Nota sobre Publicidad y Proceso", Revista del Poder Judicial, No XI, CGPJ: pp. 115-130.

Peral, María (2006): "Configuración General del Derecho a la Libertad de Comunicar y Recibir Información”, Cuadernos de Derecho Judicial: ejemplar dedicado a justicia y medios de comunicación, $\mathrm{N}^{\circ} \mathrm{XVI}$ : pp. 217-228. 
Pérez Morate, Jesús Ernesto (1999): "El Juez ante la Crítica Pública”, Revista del Poder Judicial, Número Especial XVII: p. 288.

Pérez Ruiz, Agustín, Ferreiro Bahamonde, Xulio (2006): "La Protección de la Víctima en la Vista del Juicio Oral”, en GonzÁlez-Cuéllar N. (edit.) Investigación y Prueba en el Proceso Penal (Madrid, Constitución y Leyes S.A) pp. 283-302.

Prat Westerlindh, Carlos (2013): Relaciones entre el Poder Judicial y los medios de comunicación (Valencia, Tirant lo Blanch).

Quintero Olivares, Gonzalo (1999): "Libertad de Prensa y Protección de la Independencia e Imparcialidad Judicial”, Revista del Poder Judicial, No Extraordinario 17, sobre Libertad de Expresión y Medios de Comunicación: pp. 335-360.

Rodríguez Bahamonde, Rosa (2000): La Libertad de Información y el Secreto de Instrucción (Granada, Editorial Comares).

Rodríguez Ramos, Luis, Álvarez Pérez, Terenciano y Rodríguez, Pedro (1985): "La Publicidad del Sumario", en Libertad de Expresión y Derecho Penal (Madrid, Editorial Edersa) pp. 157-202.

Rodríguez Ramos, Luis (2012): "La Actual Ficción del Secreto de las Actuaciones Sumariales como Conflicto de Derechos y de Poderes (Ponencia)", en Ovejero, pp. 145-159

Roxin, Claus (1999) "El Proceso Penal y los Medios de Comunicación", Revista del Poder Judicial, $\mathrm{N}^{\circ}$ 55: pp. 79-94.

Valldecabres Ortiz, María Isabel (2004): Imparcialidad del Juez y Medios de Comunicación (Madrid, Editorial Tirant lo Blanch).

Yoldi, José (2012): Ana María (edit), La Presunción de Inocencia y los Juicios Paralelos (Madrid, Editorial La Ley).

\section{NORMAS CITADAS}

Convención Americana de Derechos Humanos, 18 de julio de 1978.

Constitución española, 31 de diciembre de 1978.

Constitución de Cádiz de 1812.

Convención Europea de Derechos Humanos (3 de septiembre de 1953).

Código Penal alemán, de 15 de mayo de 1871.

Naciones Unidas, Asamblea General, Declaración Universal de Derechos Humanos (10 de diciembre de 1948).

Instrucción 3/2005 (7/4/2005), sobre las Relaciones del Ministerio Fiscal con los Medios de Comunicación.

Directiva 2012/29/ UE del Parlamento Europeo y del Consejo (25/10/ 2012).

Ley 35/1995 (11/12/1995), de Ayuda y Asistencia a las Víctimas de Delitos Violentos y Contra la Libertad Sexual.

Ley de Enjuiciamiento Criminal (14/9/1882).

Ley Orgánica 6/1985 (1/7/1985), del Poder Judicial.

Ley Orgánica 19/1994 (23/12/1994), de Protección a Testigos y Peritos en Causas Criminales.

Ley Orgánica 10/1995 (23/11/1995), del Código Penal. 
Ley Orgánica 5/2000 (12/1/2000), Reguladora de la Responsabilidad Penal de Menores. Pacto Internacional de Derechos Civiles y Políticos, 23 de marzo de 1976.

Reglamento 1/2005 (15/9/2005) de los aspectos accesorios de las actuaciones judiciales.

\section{JURISPRIDENCIA CITADA}

\section{Corte Europea de Derechos Humanos}

CEDH No 332/57, LAWLESS V. IRLANDA, de 14 de noviembre de 1960.

CEDH No 4451/70, GOLDER V. REINO UNIDO, de 21 de febrero de 1975.

CEDH No 6538/74 THE SUNDAY TIMES V. REINO UNIDO, de 26 de abril de 1979.

CEDH No 8273/78, AXEN V. ALEMANIA, de 8 de diciembre de 1983.

CEDH No 7984/77, PRETTO AND OTHERs V. ITALIA, de 8 de diciembre de 1983.

CEDH No 7819/77 y 7878/77, CAMPBELL AND FELL V. REINO UNIDO, de 28 de junio de 1984.

CEDH No 8209/78, SutTer V. Suiza, de 22 de febrero de 1984.

CEDH No 11508/85, BARFORD V. DINAMARCA, de 22 de febrero de 1989.

CEDH No 11454/85, KOSTOVSKI V. PAÍses BAJOS, de 20 de noviembre de 1989.

CEDH No 13585/88, THE OBSERVER AND GUARDIAN V. REINO UNIDO, de 26 de noviembre de 1991.

CEDH No 12433/86, LÜDI V. SUIZA, de 15 de junio de 1992.

CEDH No 1377/88, Thorgeir Thorgeirson V. IsLANDIA, de 25 de junio de 1992.

CEDH No 15974/90, PRAGER AND OBERSCHLICK V. AUSTRIA, de 26 abril 1995.

CEDH No 19983/92, DE HAES AND GIJSELS V. BÉLGICA, de 24 de febrero 1997.

CEDH No 21363/93, VAN MECHELEN V. PAÍsES BAjos, de 23 de abril de 1997.

CEDH No 24888/94, V. v. EL REINO UNIDO, de 16 de diciembre de 1999.

CEDH No 31457/96, NEWs VERLAGs GMBH \& CO.KG V. Austria, de 11 de enero de 2000.

CEDH No 48898/99, PeRna V. Italia, de 25 de julio de 2001.

CEDH No 31611/96, NiKULA V. FinLANDIA, de 21 de marzo de 2002.

CEDH No 40660/08 y 60641/07 VON HANNOVER V. ALEMANIA, de 7 de febrero de 2012.

\section{Tribunales Estados Unidos}

BeRG V. MinNeAPOLIS StaR \& TRIBUne Co., 79 F Supp. 957 (Minn.1948).

UNITED STATES V. REYNOLDS, 345 U.S. 1 (1953).

IRVIN V. DOWD, 366 U.S. 717 (1961).

RIDEAU V. LOUISIANA, 373 US 723 (1963).

COX V. LOUISIANA, 379 US 559 (1965).

ESTES V. TEXAS, 381 U.S. 532 (1965).

SHEPPARD V. MAXWELL, 384 U.S. 333 (1966).

Nebraska PRESS AsSN. V. StUART, 427 U.S. 539 (1976).

TOTTEN V. UNITED STATES, 92 U.S. 105 (1876).

NEW YORK TIMES Co. V. UNITED STATES, 403 U.S. 713 (1971).

CoX BroadCAsting Corp V. COHN, 420 U.S. 469 (1975). 
Weinberger V. Catholic Action Of HaWait, 454 U.S. 139 (1981).

UNITED STATES V. GRACE, 461 U.S. 171 (1983).

DOW JONES \& CO., INC. V. SIMON, 488 U.S. 946 (1988).

Tribunal Constitucional Español

STC 6/181.

STC 30/1982.

STC $13 / 1985$.

STC 30/1986.

STC 96/1987.

STC 36/1991.

STC 65/1992.

STC $168 / 1995$.

STC $21 / 2000$.

STC $139 / 2001$.

STC $155 / 2002$.

STC $158 / 2003$.

STC 54/2004.

STC 56/ 2004.

STC 57/2004.

STC $148 / 2005$.

STC $1 / 2006$.

STC 127/2010.

STC 143/2010.

STC 53/2013.

STC 23/2014.

AUTO 195/1991.

Tribunal Supremo Español

STS 1646/1994.

STS $168 / 1995$. 